\title{
Saúde vulgar e fabricação do corpo a partir de Georges Canguilhem
}

\author{
Vulgar health and body fabrication from Georges Canguilhem ${ }^{1}$
}

\author{
CARLOS ESTELLITA-LINS \\ Pesquisador na Fiocruz/Fundação Oswaldo Cruz. Doutor. \\ cefestellita@gmail.com
}

\section{RESUMO}

O texto parte de uma conferência de Canguilhem sobre o estatuto do conceito de saúde. Trata-se de uma exegese da citação de Epicteto nas Entrevistas (Livro II, 17) que busca explicitar a dupla dimensão da saúde como questão filosófica e como conceito vulgar. Busca-se articular esta formulação tardia e singular da obra de Canguilhem em seu projeto de uma história das ciências da vida compreendida como tarefa filosófica. Neste sentido cabe evocar questões centrais de sua tese Normal e Patológico - especialmente a disjunção entre o par antinômico saúde e doença e a dupla cromática fisiologiapatologia. Enquanto conclusão é oferecida uma articulação do problema com a crisecovid em curso, entendida a partir de impasses do campo biomédico e respostas insatisfatórias das ciências sociais e da filosofia.

Palavras-chave: Canguilhem. Corpo. Conceito de saúde. Pandemia. Epicteto.

\begin{abstract}
The text is part of a conference by Canguilhem on the status of the concept of health. It is an exegesis of the quote from Epictetus in the Interviews (Book II, 17) that seeks to explain the double dimension of health as a philosophical issue and as a common concept. The aim is to articulate this late and singular formulation of Canguilhem's work in his project for a history of the life sciences understood as a philosophical task. In this sense, central issues of his Normal and Pathological thesis should be evoked especially the disjunction between the antinomic pair health and disease and the chromatic physiology-pathology pair. As a conclusion, an articulation of the problem with the ongoing crisis is offered, understood from the impasses in the biomedical field and unsatisfactory answers from the social sciences and philosophy.
\end{abstract}

Keywords: Canguilhem. Body. Health concept. Pandemic. Epicteto.

\footnotetext{
1 Artigo submetido para avaliação em 15 de outubro de 2021 e aprovado em 12 de novembro em 2021.
} 
Rev. Interd. em Cult. e Soc. (RICS), São Luís, v. 7, n. 2, p. 55- 79, jul./dez. 2021

ISSN eletrônico: 2447-6498

\section{INTRODUÇÃO}

O texto parte de uma conferência de Georges Canguilhem sobre o estatuto do conceito de saúde. Trata-se de uma homenagem da Universidade de Estrasburgo, local onde lecionou, redigiu sua tese intitulada Normal e Patológico e lugar onde profere a palestra a convite de Lucien Braun, em maio de 1988.

A reflexão de Canguilhem trata de uma questão importante e esquecida. Aborda um "conceito vulgar" de saúde em suas relações com o questionamento filosófico sobre a saúde. Vulgar significa trivial e comum. Isto ganha novo relevo se observarmos a profunda reflexão de Canguilhem sobre os conceitos científicos em torno de normal e patológico. Desde a redação de sua tese, quase 45 anos antes, busca explicitar a relação entre filosofia, ciência e senso comum. Neste ínterim, alguns textos de orientação filosófica analítica buscaram um conceito de saúde tributário do campo científico. Por motivos pouco evidentes, não se dá nenhum debate com a teoria de Canguilhem, evento que será especialmente explicitado por Élodie Giroux (2010; 2012). É preciso assinalar sobretudo que saúde e doença são ao mesmo tempo "experiências" e "experimentos", o que aponta para uma apropriação do domínio crítico kantiano da Erfahrung - questão complexa do pós-kantismo e das filosofias da vida. Por outro lado, cabe suspeitar que promova uma reflexão de caráter fenomenológico sobre a saúde vulgar, ainda que o autor não reivindique esta influência, talvez mais visível na tese de medicina (SOUTO, 2021).

Não se pode compreender esta reflexão tardia de Canguilhem, cujo curto texto recupera a palestra e retoma temas abandonados, senão contextualizando o privilégio e o lugar dos conceitos científicos que pertencem ao campo do conhecimento. Esta copertinência jamais anula ou elimina uma dimensão axiológica, isto é, moral, ética e política, de avaliação da vida pela própria vida. Este é um fulcro central da reflexão de Canguilhem acerca das ciências da vida, que não hesita em situar uma dimensão propriamente filosófica. Como afirmou:

a consciência sensível imediata da vida orgânica não é, por si mesma, ciência desse mesmo organismo (...) Talvez seja por isso que até hoje a patologia levou tão pouco em consideração essa característica da doença: de ser realmente para o doente uma forma diferente de vida. É claro que a patologia tem o direito de suspeitar e de retificar a opinião do doente que pensa saber também - pelo fato de se sentir diferente - em que e como ele e ela diferem. E só porque o doente se engana manifestamente a respeito do segundo ponto 
Rev. Interd. em Cult. e Soc. (RICS), São Luís, v. 7, n. 2, p. 55- 79, jul./dez. 2021

ISSN eletrônico: $2447-6498$

não se pode concluir que ele se engane também a respeito do primeiro. (CANGUILHEM, 1978, p. 66)

Em sua vasta obra, fundadora da história das ciências da vida (do termo e do projeto rigoroso), interessa ao autor compreender o desaparecimento da noção-conceito de saúde dos tratados de fisiologia emergentes no início do século XX. Acho cabível falar em uma demissão científica do conceito de saúde. Para Canguilhem, os médicos lidam com o normal e o patológico, experiências que não equivalem de nenhum modo aos conceitos de saúde e doença. O fisiologista faz experimentação e engendra conceitos de regulação sem que entenda sua ciência como representante de conceitos de saúde. As ciências do patológico tampouco seriam donas das doenças.

Claude Bernard convida a largar "divagações como vida, morte, saúde, doença" e se deter nas condições fisiológicas próprias do fenômeno estudado. Tamanha autoridade poderia sancionar argumentos para recusar ao conceito de saúde a qualidade de científico, suspeita Canguilhem, assumindo a resposta afirmativa. Ernest Henry Starling (1866-1827) foi um dos principais formuladores do "hormônio" e da endocrinologia, além do conceito de homeostasia. Publicou a primeira edição de um Tratado de Fisiologia em 1912, sem deixar constar o termo "saúde", e que permanece excluído na reedição de Lowatt Evans (chegou a ter vinte edições). Tampouco a Physiologie de Charles Kayser (1899-1981) encontra lugar para a noção, sugerindo que o conceito de saúde havia sido definitivamente banido das ciências médicas no início do século XX. O mesmo Starling utiliza a expressão "the wisdom of the body" em 1923, secundado por Bradford Cannon (1871-1945), deixando bem claro que entende a regulação orgânica de modo muito específico, irredutível a um mecanismo. Neste sentido coloca Descartes contra si próprio, como ocorre na sexta meditação, e anuncia os raciocínios de Raymond Ruyer sobre o círculo vicioso cibernético (CANGUILHEM, 2002, p. 55-56).

Quando Canguilhem se insurge contra o termo "saúde pública", não é somente porque seria uma hipocrisia filosófica, espécie de má fé sartreana com roupas keynesianas. Ao sugerir que seria melhor falar em "salubridade pública" e desconfiar de um projeto que se apresenta coletivo sem poder efetivamente realizar-se como tal, coloca uma questão de aparência transcendental. O filósofo pergunta por um fundamento ético valorativo do vivente, ao que a biopolítica de Foucault retruca com 
Rev. Interd. em Cult.e Soc. (RICS), São Luís, v. 7, n. 2, p. 55- 79, jul./dez. 2021 ISSN eletrônico: $2447-6498$

uma exigência imanente de entender enquanto saber-poder este projeto do ocidente moderno (engendrando formas diferenciadas de governamentalidade). Aqui discípulo e mestre estão bem mais próximos do que parece ou se verifica na literatura secundária.

A tecnociencia subsumiu práticas científicas biomédicas e a biologia molecular unificou bastante o laboratório. Isto não invalida a especialização bipartite descrita sob fisiologia e patologia. Hoje, evidentemente esta lide com a questão nominal da saúde pode ser acolhida de modos distintos, concorrentes ou complementares, todos presentes na atualidade. Ou bem "a saúde" não é assunto biomédico e seria científico calar; ou saúde é assunto menor, relegada para ciências sociais incapazes de medir e tomar decisões. Ou ainda, o que me parece mais próximo de Canguilhem - a saúde permanece uma questão filosófica maior articulada, inclusive ou sobretudo, pelo conceito vulgar de saúde.

Seguindo o fio do texto é legítimo perguntarmos se a tentativa de definir, conceituar e pensar a saúde teria sido abandonada na ciência, para somente então ser mantida pelo vulgo e por certa visada filosófica. Trata-se de uma disputa, de um complemento ou de suplemento? Houve uma foraclusão da saúde no fazer científico contemporâneo que obrigaria a reconhecermos sua intrusão delirante? A rigor vivemos em meio a uma saraivada de enunciados sobre saúde. Surgiram instituições, empresas e políticas que se reivindicam legítimas pala falar em saúde. Escapa ao nexo presente examinar isto, pois a questão se coloca na demissão mesma da ciência, doravante desincumbida de uma avaliação ético-política. Suponho que a filosofia implícita na história das ciências da vida se encarrega exatamente de discutir as pretensões do conhecimento e as parcerias que foi capaz de fazer (BRAUNSTEIN, 2014).

\section{ACOMPANHANDO O TEXTO DE CANGUILHEM}

Encontramos no texto uma rapsódia filosófica que segue as aventuras do conceito filosófico de saúde centrado no silêncio, na quietude, na serenidade dos órgãos integrantes do corpo. Estes personagens não estão em conflito ou pelo menos nada sabemos desta erística. A ausência de dor tinha sido o modelo utilizado para afirmar que saúde é o silêncio dos órgãos. Os personagens filosóficos convidados por Canguilhem trazem surpresas, como a presença de René Descartes na cabeça da série... o que seria 
Rev. Interd. em Cult. e Soc. (RICS), São Luís, v. 7, n. 2, p. 55- 79, jul./dez. 2021 ISSN eletrônico: 2447-6498

paradoxal se não atentássemos para a possibilidade de outras intepretações do corpo em Descartes. Reivindica-se um foco na verdade do corpo. Trechos obscuros cartesianos apontam para o corpo como produtor de verdade, sem precisar ser heideggeriano quanto à verdade, diz Canguilhem (2002, p. 53).

Depois de Epicteto, que discutiremos abaixo, encontramos o cirurgião René Leriche junto com Paul Valery na lista de aliados. Eles teriam entronizado a fórmula do silencio corporal como fundamento, que marca Normal e Patológico. Igualmente, o emérito professor de História da Medicina, Charles Daremberg (1817-1872) e o dicionário de Émile Littré2 (1801-1881) reforçam esta argumentação, ambos ligados à fisiologia experimental bernardiana, ambos acompanhando Augusto Comte no debate sobre normal e patológico. A relação da vida com a saúde, entendida enquanto gênese de valores, também recebe influxo dos poetas criadores: Henri Michaux, Villiers de l'Isle Adam, Mallarmé e Antonin Artaud. Parece-me que são convocados enquanto filósofos que fazem ponte com o pensamento comum.

"A saúde é um tema filosófico frequente na época clássica e no século das luzes", resume Canguilhem, abordada "quase sempre" de modo semelhante. Diderot, na carta aos cegos, Leibniz, na Teodicéia e sobretudo Kant, no Conflito das Faculdades retomam a seu modo certo lugar comum da filosofia dissertando sobre saúde: a isenção de doença equivale à saúde. Isto que é tido por alguns teóricos anglo-saxões como um postulado lógico formal, "saúde igual à ausência de doença", será colocado em perspectiva. A história da filosofia, com certas ontologias, e a história da medicina, através de uma ontologia do mal, construíram a disjunção entre saúde e doença de modo laborioso e intrincado. Porém o campo experimental científico estabeleceu continuidades ou homogeneidades.

Cumpre notar que Canguilhem deixou Kant de fora do debate principal na tese, mas reconhece seu "desleixo" em 1966 - o enunciado crítico de que "man fült sich wohl im Wohl" ou seja, não sentimos o bem-estar mas somente seu impedimento - seria uma síntese de sua démarche anterior em que a patologia e a clínica originam a medicina. Contudo, o filósofo de Königsberg, icônico relógio saudável, estava enfermo ao redigir

\footnotetext{
2 Helenista e latinista como Daremberg, foi editor de obras completas de Hipócrates.
} 
Rev. Interd. em Cult. e Soc. (RICS), São Luís, v. 7, n. 2, p. 55- 79, jul./dez. 2021

ISSN eletrônico: $2447-6498$

Fakultaten Streit ${ }^{3}$ e fez um longo comentário sobre medicina e saúde na parte final do texto que trata da faculdade de Medicina. Esta obra tardia de Kant será abordada em algumas ocasiões por Canguilhem (1990; 2002). Kant afirma que podemos nos sentir bem, mas não podemos com isto saber que estamos bem. Julgar a partir do sentimento de bem-estar vital permite apenas que o homem afirme que está aparentemente bem. Há uma impossibilidade de exprimir que o homem está bem.

Não se trata apenas de um lembrete da distinção entre o esquematismo dos conceitos puros do entendimento e o sentimento de bem-estar. Para uma filosofia da saúde, sob aparente simplicidade, temos a "colocação da saúde como objeto fora do campo do saber". Se endurecermos o enunciado descobriremos que para Kant não há ciência da saúde (na acepção estrita da possibilidade de um conhecimento puro e $a$ priori). Neste sentido se esclarece um dos pontos de partida de Canguilhem - a saúde não é um conceito científico, é um conceito vulgar e também uma pergunta filosófica (Canguilhem, 2002)

Embora seja injusto com Nietzsche e Canguilhem não destacar aqui seu glorioso encontro, que representa certa auseinandersetzung intempestiva, penso que a questão da vida enquanto problema filosófico maior na obra de Canguilhem se deve mais à Nietzsche do que às filosofias da vida subsequentes.

Não cabe desenvolver o assunto, que o próprio autor evita, mencionando brevemente vários especialistas em Nietzsche que se dedicaram a destrinchar os aforismos sobre a ligação essencial de saúde, doença e pensamento. Importa aqui reconhecer uma interpretação pouco usual e de certo modo estranha ao nietzscheísmo francófilo. Nosso Frederico furioso é aproximado de René Descartes a despeito do dualismo barroco arquicriticado (Deleuze já havia criado um Spinoza nietzschiano). O problema central é da retitude do corpo. Segundo Canguilhem "saúde" resume para Nietzsche: "retitude, fiabilité, completude". Canguilhem sublinha uma passagem nietzschiana em que o corpo é dito rechwinklig (feito com esquadro) e fala do sentido da terra (CANGUILHEM, 2002, p. 55). Mais do que verdade do corpo há uma sabedoria do corpo que é sua retitude. O corpo é uma Grande Razão. 4

\footnotetext{
3 O Conflito das Faculdades foi publicado em 1792 e trata da relação da teologia com filosofia, direito e medicina. Tornou famosa a máxima kantiana: "A cama é o ninho de uma multidão de doenças".

4 Caberia aproximar esta ênfase na retidão do corpo da questão da veracidade ou probidade (Wahrhaftigkeit) em Nietzsche, que se coloca enquanto obediência ao corpo e sua Grande Ratio.
} 
Rev. Interd. em Cult. e Soc. (RICS), São Luís, v. 7, n. 2, p. 55- 79, jul./dez. 2021

ISSN eletrônico: 2447-6498

O corpo é ao mesmo tempo um dado e um produto afirma Canguilhem retomando tanto Nietzsche quanto Descartes (CANGUILHEM, 2002, p. 59) O corpo é um fenômeno, um fato, uma evidência e um texto. Nesta nuvem semântica tomamos o corpo como dado. Mas quem dá? O que é este ato de doação? Devemos examinar os problemas husserlianos ou heideggerianos acerca da doação fenomenológica? Isto pode conversar com o dom ou com a hospitalidade na etnologia contemporânea?

Um sentido mais evidente seria aquele da primeira crítica kantiana. Onde encontramos leis na natureza é porque as prescrevemos a ela - a interpretação de Kant vem da necessidade de repensar uma natureza divina que constituiria a natureza humana. A interpretação de Nietzsche acerca desta passagem é literal neste ponto: devemos desconfiar de uma projeção antropomórfica de leis imputadas à natureza. Neste sentido compreendemos por que para Nietzsche o corpo não é algo dado na natureza, mas uma razão que critica a própria tarefa crítica da razão pura.

Contudo para Canguilhem o que importa neste corpo dado, herdado e mantido por "seu titular", o vivente, são os "erros do patrimônio". Sua reflexão sobre a natureza é sempre erudita assim como sua apropriação da erística conceitual entre a monstruosidade e o monstruoso mostra-se muito lúcida. Ambos estão dados - o corpo monstruoso e o corpo a que se imputa monstruosidade. Se pudermos falar em um vitalismo contemporâneo, em uma resistência ao totalitarismo dos mecanicistas, trata-se da vida como abertura ao erro. O que anima o vivente e desconfigura qualquer máquina tida por modelo, não é o espírito das leis, mas a transgressão feliz das leis. Note-se que o corpo "dado" não é absolutamente passivo nem somente regulado por uma ecologia ambiental evolucionista. Há um estranho conatus operando.

Corpo é atividade de inserção num meio, para Canguilhem. Se o corpo é igualmente situado e inserido, então torna-se um corpo ativo em enésima potência. A fabricação do corpo ocorre sobretudo porque um corpo é capaz de criar novas normas, praticar-impor e transmitir novas formas de existir em um meio-ambiente inédito. A importância do conceito de milieu interieur é bastante enfatizada na história das ciências da vida a partir de Canguilhem.

O organismo se descola do indivíduo e torna-se um sistema dentro de sistemas, talvez uma estrutura (termo estranho ao autor) - vida é negociação adaptativa entre um 
Rev. Interd. em Cult. e Soc. (RICS), São Luís, v. 7, n. 2, p. 55- 79, jul./dez. 2021 ISSN eletrônico: 2447-6498

meio intracelular com o meio interno das mensagens intra-orgânicas 5 - fluidos, géis, moléculas mensageiras, campos elétricos, forças de van der Waals (geralmente materializado no sistema neuro-imuno-endócrino). Certamente o meio-ambiente de Jakob von Uexküll (1864-1944) é o terceiro elemento - um mundo circunvizinho (Umwelt), que pode incluir família, comunidade, sociedade, nação, continente e biosfera. Canguilhem faz um comentário sobre o carrapato (tique) 6 existencialmente "situado" numa ecologia de doença planetária. Sua digressão resgata o carrapato de Uexküll por caminho mais próximo da biosemiótica do que na noção de animais "pobres em mundo" (Weltarm). O que Canguilhem aprende do biólogo estoniano é que "é próprio do vivente compor seu meio-ambiente" (CANGUILHEM, 2015, p. 300). Vida é neguentropia permanente num regime entrópico paradoxalmente "eterno".

Longe de buscar uma "irracionalidade" ou misticismo na eterna luta do mecanismo com o vitalismo dentro da biomedicina, nosso filósofo de Castelnaudary encontra um papel para o questionamento filosófico no interior de uma história das ciências da vida. Trata-se de um programa ético sem ser bioético, moral sem ser moralista e político sem ser claramente partidário. Se há uma tendência da filosofia em buscar uma verdade do corpo, Canguilhem entende a tardo-modernidade e sua medicina mundializada e globalizada enquanto uma passagem sub-reptícia da "significação de verdade" à facticidade. Ocorre um embate pois existe pensamento no corpo.

Isto significa que a saúde se torna objeto de um cálculo. Parece que a questão tem menos uma ressonância fenomenológico existencial e mais uma dimensão éticopolítica. Sem dúvida, o texto afirma que certa iniciativa administrativa (conceito vulgar) entende o problema da saúde de um homem "que pertence a uma comunidade social ou profissional" através do ocultamento do sentido existencial pela contabilidade.

Porém, é mais relevante enxergar o problema implicado: "o discurso da higiene, disciplina médica bastante tradicional, doravante recuperada e travestida por uma ambição sócio-política-médica de regramento da vida dos indivíduos" pretende falar pela saúde. Canguilhem inclusive menciona a clássica definição da OMS/WHO (Organização Mundial da Saúde) ao lado de Tissot et Ettienne Tourtelle, mas não

\footnotetext{
5 Ao meio interno de Claude Bernard, acrescentaríamos hoje pelo menos um meio intranuclear nos eucariontes além de espaços de troca no interior das organelas, para não falar na porosidade seletiva da membrana plasmática como algo que separa, mas se integra ao meio através de redes de receptores.

6 Ácaros parasitas de várias espécies da ordem Ioxidida.
} 
Rev. Interd. em Cult. e Soc. (RICS), São Luís, v. 7, n. 2, p. 55- 79, jul./dez. 2021

ISSN eletrônico: 2447-6498

discute com Wakefield ou Engelhardt que estariam piedosamente por trás da fórmula oficial. A verdade do corpo é irredutível.

Trata-se de reconhecer que as ciências da vida admitem um regime de singularidade ainda que não exista ciência do singular para Aristóteles. Esta dimensão valorativa não pretende escamotear a política nem buscar o Soberano Bem da Ética à Nicômaco. Por esta vereda podemos admitir que a ciência não substitui a política nem é capaz de guiá-la, entretanto adquire um papel diplomático que poderíamos chamar de cosmopolítico com Isabelle Stengers (via Deleuze).

Um filósofo analítico, para quem é sempre possível discutir definições, desenvolveu um longo raciocínio sobre um "conceito científico de saúde" e outro de doença - pretende subsumir muitas enfermidades com etiologias e fenômenos heteróclitos. Não é mencionado por Canguilhem e tampouco cabe em nossa discussão. De qualquer modo representa uma via diferente não apenas porque claudica de qualquer referência histórica buscando a sincronicidade absoluta, mas porque entende a filosofia da ciência como porta-voz epistemológico daquilo que os cientistas fariam sem desprovidos de clareza ou sem plena consciência. Na história conceitual das ciências que praticavam Bachelard, Cavaillès e Canguilhem há uma busca da imanência do conceito (ou problema) que caracteriza cada démarche regional específica na ciência. Nem todos os discursos se recobrem ou se equivalem através de uma sintaxe lógica pois não se acreditava na unidade da ciência. Boorse, ao contrário, busca uma boa definição de saúde sem admitir que isto depende de quem fala e de onde fala. Ryle imaginou que mineiros de carvão de Durham poderiam ser mais capazes, adaptados e saudáveis do que um policial inglês que se dedicasse ao exercício da mesma tarefa. Quando Boorse ironiza seu raciocínio, afirmando que nem por isso seriam menos doentes, argumenta que olhar para sua adaptação superior enfraqueceria reivindicações trabalhistas.

Fica claro que doença ou saúde não são juízos de valor ou reivindicações políticas senão quando a medicina do trabalho diz quem você deve ser e decide sozinha quem está doente (negros da mineração na África do Sul estavam sob o preconceito africâner ou estadunidense de que o preto é um escravo doentio). Estas minas indignas, que somente foram desativadas entre 1960 e 1994, produziram enfermidade no planeta, nas ilhas britânicas, nas cidades coligadas e em todos os familiares de cada trabalhador. 
Rev. Interd. em Cult. e Soc. (RICS), São Luís, v. 7, n. 2, p. 55- 79, jul./dez. 2021 ISSN eletrônico: 2447-6498

Ao mesmo tempo em que "o operário cessa de se sentir objeto num meio de constrangimento para sentir-se sujeito em um meio de organização;" ele também adapta o meio de trabalho hostil enquanto se submete às suas exigências (CANGUILHEM, 2015, p. 301). Para Canguilhem, não somente cada adoecimento e cada busca da grande saúde pode ser singular, como existe quid juris uma dimensão normativa da vida, do corpo e do "vulgo" enfermiço. Ao recusar qualquer noção de adaptação e demonstrar a pregnância da regulação, Canguilhem problematiza uma relação do vivo com a máquina e com a relação de produção opressiva. O singular articula-se com uma multiplicidade, ao contrário do particular, que se opõe a uma universalidade. É aliás nesta direção que Canguilhem indaga se grupos profissionais são capazes de engendrar um conceito de saúde vulgar. Não cabe repetir: roma locuta quaestio finita. O conhecimento científico não deve calar o vulgo pois serve para transformar, para brigar e resistir, para a política.

Mas, não estaríamos desprezando a medicina pergunta-se o historiador-filósofo? Há um risco de "elocubração", diz ele, "ao pedirmos à filosofia que reforce nossa proposição de sustentar a saúde como um conceito, ao qual a experiência vulgar confere o sentido de uma permissão de viver e agir ao bom grado do corpo" (CANGUILHEM, 2002, p. 66). Entretanto, há precedentes. Talvez o corpo já tenha tido ou sido este poder para agentes comunitários de saúde tributários da revolução francesa (influenciados por médicos), ou ainda nos conflitos entre a ideologia de especialistas e generalistas, sem esquecer a querela de ecologistas e naturistas defensores de uma "saúde selvagem privada" (Ivan Illich) contra a saúde cientificamente condicionada.

Há, portanto, problemas na história das ciências da vida que bagunçam a partilha entre conceitos de saúde egressos da experiência vulgar e a arte terapêutica parcialmente hibridizada, reconhece Canguilhem. Pode-se ainda atacar seu curioso percurso de algumas maneiras. Menciono as duas mais óbvias. 1) A história das ciências da vida reconstruída por seus afins não teria incorporado suficientemente a transnacionalização do campo biomédico, deixando redes e circuitos mais amplos sem lugar. 2) A sociologia e antropologia médica incorporaram e aprofundaram muitas contribuições afins, mas já teriam ultrapassado a impessoalidade da pessoa comum que adoece. 7

A tese forte de Canguilhem consiste em reivindicar a parceria entre um pensamento vulgar, ou talvez selvagem, e o campo científico, que se encontra

\footnotetext{
${ }^{7}$ A antropologia social é a filosofia com gente dentro, teria dito Tim Ingold.
} 
Rev. Interd. em Cult. e Soc. (RICS), São Luís, v. 7, n. 2, p. 55- 79, jul./dez. 2021 ISSN eletrônico: $2447-6498$

legitimado para traduzir saúde e doença em normal e patológico. Afirma, portanto, que "assumir a saúde como verdade do corpo em sentido ontológico admite igualmente a verdade em sentido lógico", nem que seja como garantia ou "paraquedas".

Parece sugestivo que Canguilhem tenha se debruçado anteriormente sobre as teses bergsonianas da inteligência da vida na evolução criadora. Evidentemente o corpo vivido não é um objeto, contudo para o homem, viver também significa conhecer.

O corpo vivido da fenomenologia francesa foi frequentemente tematizado em sua duplicidade, equivocidade, ambivalência, ambiguidade, paradoxo, aporia. Para Canguilhem, talvez a ambiguidade seja "uma armadilha". Ele aposta no Merleau-Ponty póstumo, que enfatiza uma abertura do corpo ao exterior, ao não-fechado do dehors radical - possivelmente em uma releitura do cartesianismo via Husserl. Importa reconhecer "uma parte do corpo humano inacessível aos outros, acessível somente ao seu titular".

A saúde é uma questão filosófica. Merleau-Ponty afirma em $O$ Visível $e$ o Invisivel que "a filosofia é o conjunto de questões onde aquele que pergunta é colocado em questão pela pergunta". Canguilhem faz trabalhar esta fórmula nas ciências da vida assumindo o vivente como actante primordial que pergunta, se pergunta e se reconhece como resposta à pergunta. Não se trata de uma filosofia do sujeito, mas talvez do conceito, não se trata de um percurso fenomenológico evidente, mas certamente correlato.

\section{Buscando uma exegese do trecho}

Gostaria, portanto, de examinar questões a partir da discussão das três primeiras linhas deste texto pouco comentado ou desapercebido de Canguilhem. Trata-se de uma exegese da citação de Epicteto nas Entrevistas (Livro II, 17) que busca explicitar a dupla dimensão da saúde como questão filosófica e como conceito vulgar. Cumpre notar que qualquer referência a Epicteto neste contexto amplo da saúde é inusitada.

Esta passagem, que funciona como a abertura de uma ópera wagneriana pois contém todo o desenvolvimento da obra, não é uma ilustração erudita. Canguilhem não se propõe evidentemente nem a discutir o livro II nem a entrevista 17 em questão, mas 
Rev. Interd. em Cult.e Soc. (RICS), São Luís, v. 7, n. 2, p. 55- 79, jul./dez. 2021

ISSN eletrônico: $2447-6498$

claramente recorta uma passagem mínima que já comporta bastante de seu argumento sobre um direito do vulgo ao conceito de saúde. Aqui situa-se todo aquele que vive, é ou tem um corpo (sarx ou soma) e adoece. Se filosofar é aprender a morrer, nos ensaios de Montaigne, para Canguilhem, adoecer é conceder direito de cidadania à experiência de doença (e conceitos derivados). Adoecer é ensinar a se curar e ensinar a ficar novamente doente - de onde se depreende a importância de um conceito vulgar de saúde. Não existe patologia da máquina, afirma. Em última análise adoecer é um luxo para o pensamento filosófico informado pelo vivente, segundo Canguilhem.

Epicteto é um filósofo estóico tardio, que sobrevive através de doxografia ou compilação por Arriano e comentários como de Simplicius, Marco Aurélio e outros anônimos. Todos os outros manuscritos foram desautorizados por serem apenas cópias de um arquétipo conservado da biblioteca bodleiana de Oxford. Suas principais obras são o Manual ou Enchiridion Epiktetou composto de 54 capítulos curtos; e as entrevistas ou Diatribai, de que restam quatro livros de oito originais. A edição monumental de Y. J. Schweighäuser, publicada em Leipzig em 1799-1800, permanece ainda a edição canônica ou base indispensável de qualquer estudo sobre Epicteto. Em inglês, a edição Loeb é emblemática, com tradução de W.A. Oldfather publicada em 1925. Na França existiu uma edição importante com tradução de V. Courdaveaux (1862, reimpressa em 1908) atualizada por ocasião da tradução dos dois primeiros livros das Entrevistas com Joseph Soillée (baseada na versão de H. Schenkel), que teve publicação póstuma em 1943 e 1949. Muitas edições recentes estão disponíveis (Amand Jagu, Jean-Baptiste Gourinat, Pierre Hadot, d'Jeronian), inclusive uma tradução do Manual para o português, de Aldo Dinucci e Alfredo Julien da Universidade de Sergipe.

O estoicismo é mais do que a recomendação "saudável": sustine et abstine. - há uma reflexão anti-aristotélica sobre o tempo, os silogismos, o corpo e incorporais, o sentido, etc. circulando de modo forte no antigo estoicismo grego e nos estoicos romanos. Tampouco escapa a percepção de que as versões de Epicteto disponíveis testemunham sua relação com Galeno e a medicina da época - são trufados de comentários sobre doença, saúde e tratamentos. Fico satisfeito em assinalar que se trata de uma questão colocada por um filosofo estoico que se esmera nos aspectos ditos morais, embora não se restrinja a isto. Não é difícil imaginar alguma influência de Alain, filósofo admirador de Epicteto e modelo para o jovem Canguilhem. A proairesis 
Rev. Interd. em Cult. e Soc. (RICS), São Luís, v. 7, n. 2, p. 55- 79, jul./dez. 2021 ISSN eletrônico: 2447-6498

de Epicteto chamou atenção no século XX (HAASE, 1989). Lembremos ainda que o último Foucault foi aos exercícios espirituais de Loyola para então adentrar neste território estoico, fundador de certo cuidado de si, com a ajuda de Pierre Hadot.

O texto de Canguilhem se inicia, portanto, com uma citação de Epicteto, na qual é mencionado Hipócrates (pensador, espécie de sacerdote-médico, um fundador da "medicina grega" e autor de textos filosófico-morais sobre enfermidades):

"Quem de nós não falava do que é saudável ou do que é nocivo antes da vinda de Hipócrates?"8

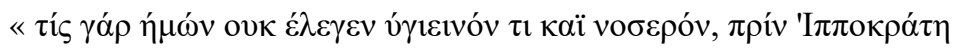
$\gamma \varepsilon v \varepsilon \dot{\sigma} \sigma \alpha l »$

Epicteto cita Teopompos de Quios, aluno de Isócrates na passagem imediatamente anterior. A autoridade de Platão é questionada por insistir em definir cada termo. Afirma-se a absoluta legitimidade dos oradores, poetas e declamadores retóricos em usar as palavras bom (agaton) ou justo (dikaion) antes de Platão, assim

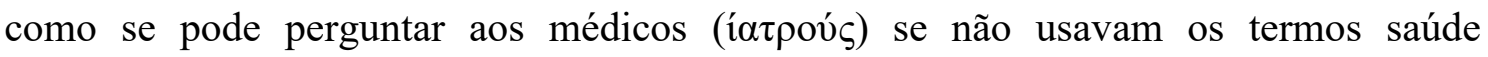

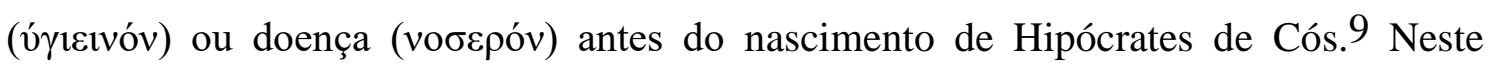
discurso fica em questão a prolepsis ( $\pi \rho \circ \lambda \eta ́ \psi \varepsilon 1 \varsigma)$, esta apreensão legítima que, contudo, necessita do saber filosófico para ser adequadamente aplicada ao caso ou circunstância. Antecipação da percepção e pré-conceito ou fantasia em chave helenística, a prolepsis poderia igualmente nos remeter ao cogito ante-predicativo e ao debate fenomenológico de Merleau-Ponty e Cassirer. Seu sentido é positivo nos estoicismos afins embora o discurso de Epicteto sublinhe a necessidade de superação da prolepsis no encaminhamento para a filosofia. A moral sustentada consiste na moderação, atingida através de não-desejar e de seguir os deuses rumo a uma ataraxia. Poderíamos pensar em uma colocação entre parêntesis, redução fenomenológica em que inclusive o conceito de noesis estóica seria cabível. A prolepsis se comunica com outros conceitos

8 "Suppose, for example, that you make the same sort of remark to the physicians: "Why, who among us did not use terms 'healthy' and 'diseased' before Hippocrates was born? Or were we merely making an empty noise with these sounds?" (EPICTETUS, 1928, p. 338-339).

9 Os comentadores não confundem Hipócrates de Cós, a que a passagem parece referir-se em função da sabedoria medicinal, com Hipócrates de Quios, matemático contemporâneo do primeiro. No caso de Psicopompos, geralmente mencionado como historiador, seria originário da ilhota de Quios, do mesmo arquipélago do dodecaneso, e igualmente um importante retórico. 
Rev. Interd. em Cult. e Soc. (RICS), São Luís, v. 7, n. 2, p. 55- 79, jul./dez. 2021

ISSN eletrônico: $2447-6498$

afins ou semelhantes, como: katalepsis, fantasia, proairesis, ennóia e noese (JAGU, 1946; PETERS, 1969, p. 164).

O que significa para Epicteto, na entrevista 17, esta pergunta sobre o direito de colocar-se antes de Hipócrates e Platão, que parecem reconhecidos como autoridades? Em ambos os casos trata-se de uma prolepsis, que seria traduzida tanto por preconceito como por uma apreensão natural originária. Seu sentido é positivo nos estoicismos afins embora o discurso de Epicteto sublinhe a superação necessária e o encaminhamento para a filosofia. A moral sustentada é da moderação do não desejar e de seguir os deuses rumo a uma ataraxia. Poderíamos pensar em uma colocação entre parêntesis, redução fenomenológica, inclusive o conceito estóico de noesis seria aplicável. A prolepsis se comunica com outros conceitos semelhantes.

Na passagem em questão Epicteto emula Psicopompos e simula curandeiros pré-hipocráticos que sabem perfeitamente do que estão falando e tem pleno direito de dizê-lo. Trata-se de uma fala em falsete ou discurso indireto que anima personagens filosóficos, semelhante ao diálogo socrático, mas nem por isso distante daquilo que o Platão da República condenava em Homero.

Neste fragmento, Epicteto reivindica o fato de que já se falava sobre saúde antes mesmo de Hipócrates. Então, a quem pertence o discurso sobre o saudável? Canguilhem, ao sugerir essa formulação quase que emblemática e muito relacionada ao título do texto, tematiza a reivindicação à legitimidade desse discurso popular. Por sua vez, Canguilhem parte da hipotética citação referindo-se ao conceito vulgar, nem filosófico nem científico. Acompanha uma "apreensão" ou pré-conceito que antecede Platão e Hipócrates. Não me parece que o estatuto dos físicos-curandeiros seja relevante para seu argumento sobre a apreensão compartilhada de uma experiência pré-filosofica. Não é sua protomedicina que garante a fala. Tanto faz que sejam pessoas comuns ou dedicadas às artes de curar, seja no raciocínio de Epicteto como no juízo epistemológico sobre visões espontâneas da saúde.

Não estamos somente fazendo barulho vazio com estas palavras pois temos

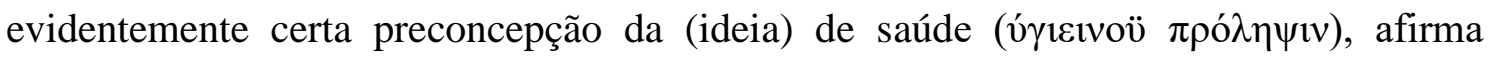
Epicteto. Contudo somos incapazes de aplicá-la. É por isso que uma pessoa diz para se

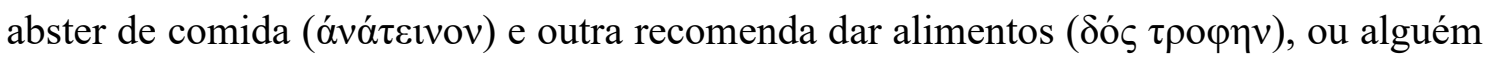
diz para cortar uma veia e sangrar ( $\varphi \lambda \varepsilon \beta 0 \tau o ́ \mu \eta \sigma o v)$ enquanto outro sugere usar ventosas 
Rev. Interd. em Cult. e Soc. (RICS), São Luís, v. 7, n. 2, p. 55- 79, jul./dez. 2021

ISSN eletrônico: 2447-6498

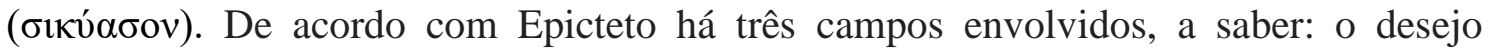

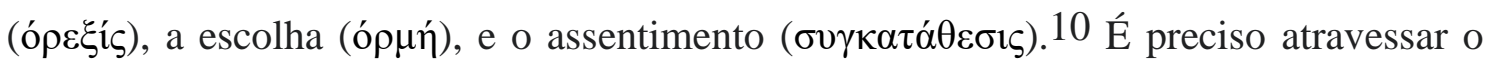
campo do desejo e considerar a escolha e o assentimento quando se trata de aplicar a sabedoria a uma determinada situação.

Se admitirmos que é possível uma definição da saúde sem nenhuma referência a qualquer saber possível, precisaremos buscar seu fundamento, afirma Canguilhem, resumindo seu intento. Cabe imaginar que empreende uma busca de prolegômenos à fundamentação do conceito comum. Não é possível responder se há privilégio de alguma instância ou se ficamos com o múltiplo. Afirma Canguilhem: “É assim que Epicteto funda uma reivindicação de pertinência popular sobre a existência de uma noção a priori do saudável e da saúde, cuja aplicação aos objetos ou ao comportamento é considerada, aliás, incerta".

Quando todos nós ou qualquer um de nós falamos de são, saudável ou de doente, talvez não possamos discorrer facilmente sobre esses conceitos. O popular tem direito filosófico a uma noção de saúde - seu conceito vulgar. Esta reflexão existe $a$ priori, independente da experiência e sem consideração pelas ciências. Teria um domínio de aplicação que consistiria nos objetos ou comportamentos. Ainda que sua aplicação seja incerta deve ser considerada legítima. Todavia, podemos falar baseados em nossos conhecimentos sobre o que é assumido enquanto normal e do que é padecido como patológico. Porém o adoecimento possui a autoridade da experiência e já representa um passo adiante. Há, portanto, pelo menos dois patamares distintos. Talvez a tendência em pensar a saúde como ausência de doença não seja lógica nem histórica, mas fenomenologicamente arraigada no conceito comum. Esta reflexão popular, sem filósofo ou especialista, ainda que incerta é importante. O popular tem direito filosófico a uma noção de saúde - seu conceito vulgar.

Se admitirmos que é possível uma definição da saúde sem nenhuma referência a qualquer saber possível precisaremos buscar seu fundamento, afirma Canguilhem, praticamente resumindo seu intento. Cabe admitir que esta busca trata de prolegômenos à fundamentação do conceito comum. Canguilhem, ao colocar essa formulação quase que emblemática e muito relacionada ao título do texto, tematiza a reivindicação à legitimidade desse discurso popular. Imagino que, sendo formado no

10 Conforme também Entrevista, III, II; 
Rev. Interd. em Cult. e Soc. (RICS), São Luís, v. 7, n. 2, p. 55- 79, jul./dez. 2021

ISSN eletrônico: $2447-6498$

interior dos debates da escola sociológica francesa, não duvida da importância de representações sociais, de uma sociologia do adoecimento, de sua memória e narrativa. Trata-se, porém, de outra ênfase, análoga ao debate sobre a filosofia espontânea dos cientistas, caro à Louis Althusser. O bom senso e o senso comum não se encontram nocauteados pelo advento do conhecimento vitorioso.

Esta reflexão existe a priori, não é independente da experiência, mas emerge sem consideração pelas ciências e interpela o discurso filosófico. Expressa-se em termos escolhidos: “(...) sobre a existência de uma noção a priori do são e da saúde”, o que faz necessário destrinchar o significado dessa noção de à priori. Um professor do Khâgne jamais confundiria o underground estóico com a revolução crítica kantiana.

Noutro sentido, o termo a priori, especialmente a partir de Kant, se opõe ao a posteriori. A posteriori é o conhecimento que se tem a partir de uma experiência. Em acepção pré-critica dizemos que um julgamento a posteriori vai da consequência para a causa. A priori, por sua vez, não depende da experiência, sendo puro, universal e necessário. Para a compreensão de um juízo a priori, de acordo com Kant, podemos afirmar: "Todos os corpos caem". Sendo desnecessário derrubar um corpo ou fazer uma experiência para constatar que todos os corpos caem. Dessa forma, todos têm algo a dizer sobre saúde, independentemente da fala autorizada dos especialistas. Hipócrates, nesse caso, desempenha o papel de um juiz a posteriori, representando a fala autorizada, tanto de médico quanto de filósofo. A prolepsis teria um domínio de aplicação que consistiria nos objetos ou nos comportamentos. Ainda que sua aplicação seja incerta, como afirma Canguilhem, deve ser considerada legítima segundo Epicteto.

Entretanto, a questão de Canguilhem pode ser traduzida da seguinte maneira: Será que a medicina moderna veio a criar conceitos científicos correlatos (norma, patologia, anomalia) puramente a partir de si mesma, ou necessita de uma instância originária? Será que necessita de outros discursos para dizer isto, evitando com sucesso falar em saúde? Se precisa de outros fatores, que fatores são e que relação estabelecem com o conhecimento positivo?

Uma história descontinuísta das ciências sugere que há conceitos científicos recortando regiões sem solução de continuidade com práticas científicas prévias ou colaterais. O surracionalismo surrealista de Gaston Bachelard por exemplo, não pretende demarcação, e sim explicação da convivência de racionalidades 
Rev. Interd. em Cult. e Soc. (RICS), São Luís, v. 7, n. 2, p. 55- 79, jul./dez. 2021 ISSN eletrônico: 2447-6498

coexistentes. ${ }^{11}$ Contudo Canguilhem reconhece a importância de uma história da teoria celular, do conceito de organismo, da fisiologia, da patologia, do conceito de reflexo, etc... A rigor, admite o paradoxo de uma anterioridade lógica do sofrimento com a patologia, possivelmente onto-teo-lógica, e uma anterioridade epistemológica da fisiologia. A solução está na captura destas duas séries sob o continuum de normal e patológico, postulado pela Escola de Paris.

Respondendo as últimas perguntas, normal é uma noção construída no domínio científico, que pode ser recapitulada através da história da ciência. Canguilhem menciona algumas vezes a história do "Princípio de Broussais" junto com o surgimento da fisiologia experimental francesa para nos mostrar as várias acepções e os vários caminhos do normal. Sua hipótese consiste em um embricamento de fatos e ideais. Uma média estatística, uma constatação prática, uma regulação não-mecânica insidiosa (fato ou ser) mas igualmente uma exigência dos viventes e uma direção da terapêutica médica (ideal ou dever-ser). Verifica-se uma exigência axiológica na saúde.

Contudo, caso se pergunte para uma pessoa se ela está normal, sua resposta nada terá a ver com a resposta de um fisiologista ou de um patologista, que com seu olhar virtualmente clínico seria capaz de dizer se o organismo está normal. São, portanto, duas visadas absolutamente heterogêneas. Segundo ele, não é simplesmente uma questão objetiva ou subjetiva. Além disso, esse é um problema de incidência epistemológica entre dois níveis que, embora sejam interdependentes, necessitam atuar em uma articulação rica em nuances. A investigação epistemológica de Canguilhem é extremamente rica e importante por sustentar uma decalagem entre ética e conhecimento, que aliás ganha novos sentidos nas zoonoses do antropoceno.

Ao tentarmos atingir a essência do Normal e Patológico, obtemos a seguinte idéia: normal, por um lado, é sobretudo um juízo de valor, uma avaliação. Só quem avalia é o vivente e, este assim o faz baseado em sua singularíssima experiência de vida e de doença. Por outro lado, o normal foi construído historicamente através de descrições científicas e alocado no curto hiato entre dois extremos de adaptação do

11 Canguilhem se inquieta com a hipótese de um surrealismo médico que substituiria a medicina pela biologia, discordando inclusive de seu discípulo François Dagognet, cf. BING, François; BRAUNSTEIN, Jean-François. Entretien avec Georges Canguilhem. In: BING, François; BRAUNSTEIN, Jean-François; ROUDINESCO, Elisabeth (Orgs.). Actualité de Georges Canguilhem. Le normal et le pathologique. Paris: Les Empêcheurs de penser en rond, 1998, p. 134-148. 
Rev. Interd. em Cult. e Soc. (RICS), São Luís, v. 7, n. 2, p. 55- 79, jul./dez. 2021 ISSN eletrônico: 2447-6498

vivente - saúde e morte. A norma é absolutamente decisiva e não provém somente da estatística. Essa descrição foi possível com o auxílio da objetividade científica, a qual se impôs à medida que delineava a fisiologia e a patologia como ciências positivas lidando com fatos purificados de qualquer valoração. O corpo patológico foi construído pela fisiopatologia.

Isso significa que, através do ponto de vista do normal, este pode ser para o fisiologista apenas um ponto de corte, a posição em uma curva; um certo evento adaptativo para o patologista; uma descrição de modificações do organismo num dado recorte ambiental e ecológico para o clínico, que aliás opera como embaixador do paciente junto à ciência. O normal sempre será algo designado através da fisiologia e da patologia. Entretanto, para o vivente envolto no objeto vida, o cuidado da saúde e da doença extrapolam normal e patológico porque informam através de valores. Dessa forma, quando o paciente faz uma auto-avaliação e não se sente normal, ele usa um critério de normalidade distinto das constantes do fisiologista, distinto dos exames do laboratório do patologista/radiologista.

Em contrapartida, o clínico, ao fazer uso da fisiologia e da patologia para examinar a vitalidade do organismo, seja um dente, uma postura errada, uma prática pedagógica na escola, sempre usará de critérios objetivos no interior de um conjunto de saberes que o fará constatar a normalidade ou a patologia. Contudo dependerá do aval axiológico do interessado maior e juiz absoluto: o doente. Entrevemos por aqui a reivindicação de Epicteto, ou seja, a importância dita "a priori" dos enunciados comuns, que Canguilhem recorta e destaca por incidir sobre a saúde. A terapêutica emerge surpreendentemente em Normal e Patológico como uma técnica de restituição do normal que depende do diálogo e do intercâmbio de juízos - radicalizando diremos que é tradução, troca, diplomacia política. O enfermo julga sempre, a vida julga durante a existência e a morte julga depois. Uma pessoa saudável nada pode julgar pois desde sempre já esqueceu.

Articular esta formulação tardia e singular da obra de Canguilhem com seu projeto de uma história das ciências da vida compreendida como tarefa filosófica autoriza a evocar questões centrais de sua tese O Normal e o Patológico especialmente a disjunção entre o par antinômico saúde e doença e a postulação de uma dupla cromática fisiologia-patologia. 
Rev. Interd. em Cult. e Soc. (RICS), São Luís, v. 7, n. 2, p. 55- 79, jul./dez. 2021 ISSN eletrônico: $2447-6498$

Ingenuamente podemos afirmar que normal e patológico é assunto do clínico que aprende a decidir sua fronteira para intervir. Igualmente que é assunto exclusivo de quem reconhece seu sintoma, ao tentar melhorar ou buscar ajuda. O tour de force oferecido consiste ao contrário, em indicar que a constituição de um projeto de medicina científica moderna, - experimental, newtoniana, kantiana etc. - fez uso da hipótese de uma comunicação necessária entre normal e patológico ao invés de afirmar imediatamente sua diferença sensível. Uma diferença de grau e não de natureza se mostrou útil e permitiu conceitos científicos. O problema da contingência e da necessidade na história das ciências está posto. Ora, a questão é que as ciências da vida, quando ousaram pensar normal e patológico, jamais o fizeram de forma arbitrária. Muito pelo contrário, o normal e o patológico são o resultado de uma história intrincada de negociações. Isso se justifica plenamente pois, para o vivente (único verdadeiro interlocutor), o que interessa é o valor da vida. O caráter aprioristico da vida como perspectiva avaliadora é originário.

Nesse sentido, o campo científico se constitui depois da magia e da feitiçaria, introduzindo-se nas terapêuticas pré-modernas posteriormente. Ou seja, as intervenções ou práticas de curar (terapêutica) não existem em função do campo científico, mas passaram a coexistir com ele e submeter-se à sua potência. O campo científico foi capturado pela necessidade de tratar e passou, então, a servi-la, dentro de negociações complexas, nas quais o valor que o paciente dá para sua doença e para sua saúde é soberano. Soberano não apenas porque a boa prática médica manda o clínico se guiar pelo paciente na terapêutica, mas porque o paciente pode ir embora, pode nunca ir ao médico, além de sempre poder usar de outros itinerários terapêuticos, como por exemplo, tratamentos tradicionais (rituais, encantados, religiosos) ou prescritos por alguém em que confia.

Ademais, é importante ressaltar a utilização de outras soluções sem fundamentos científicos, consideradas primitivas, equivocadas ou inviáveis, no entanto, demasiado humanas para realizar a experiência do valor. Há, portanto, um acordo entre a dimensão valorativa de saúde e doença e a dimensão epistemológica objetificante.

Contudo, "se nós admitirmos, por nossa vez, que uma definição da saúde seja possível sem referência a qualquer saber ou experiência, onde procuraríamos esse saber?" Com esse questionamento de Canguilhem, o projeto do texto se torna um pouco 
Rev. Interd. em Cult. e Soc. (RICS), São Luís, v. 7, n. 2, p. 55- 79, jul./dez. 2021

ISSN eletrônico: 2447-6498

mais claro. Ainda assim, é importante chamar a atenção para a sofisticação de sua escrita. A complexidade do que Canguilhem quer nos mostrar reside justamente nessa sofisticação. "Se nós admitirmos, por nossa vez..." não é, simplesmente uma questão estilística, mas efetivamente uma decisão de admitir ou não. Isso não significa que temos de admitir e nem que seja um caminho privilegiado de reflexão. No entanto, uma vez que passamos a admitir, entraremos nele, será um experimento do pensamento. É por essa razão que o questionamento da saúde como conceito é uma contribuição que está tão longe de ser uma questão simples ou óbvia. Reconhecer a continuidade entre normal e patológico ou a polaridade de saúde e doença não é tarefa do cientista.

A experiência de doença corresponde ao conceito vulgar de saúde no campo das vivências e experimentos. Como foi dito: "É impossível para o médico compreender a experiência vivida pelo doente a partir dos relatos dos doentes. Porque aquilo que exprimem por conceitos usuais não é sua experiência direta, mas sua interpretação de uma experiência para a qual não dispõem de conceitos adequados" (CANGUILHEM, 1978, p. 87-88).

Pode-se concluir que há uma parceria de personagens filosóficos e práticas científicas embaralhadas: a) dos conceitos vulgares de saúde, b) de uma filosofia dos conceitos de saúde e doença, c) de problemas científicos abordados por conceitos da fisiologia ou da patologia e ainda d) do médico clínico traduzindo o contínuo normalpatológico. São, portanto, quatro instâncias, a comunidade, o filósofo, os cientistas da biomedicina e os médicos (em cooperação e também em negociações complexas com os outros elementos). Poderíamos arriscar mais um paralelo ainda: a) prolepsis da saúde; b) sua elaboração categorial; c) o conhecimento científico; d) a ação prática;

\section{QUEM É VULGAR?}

Como vimos anteriormente, Canguilhem usa a História da Ciência para explicar a origem do conceito de normal no domínio científico - donde a dicotomia normanormatividade. Além disso, Canguilhem pertence a uma perspectiva descontinuista, na qual conta a história da ciência a partir de suas rupturas. Ao fazermos um paralelo com Foucault, aluno de Canguilhem, vemos que há uma briga entre ele e as histórias continuístas da medicina sobre o nascimento da clínica. Embora admita que tratar de 
Rev. Interd. em Cult. e Soc. (RICS), São Luís, v. 7, n. 2, p. 55- 79, jul./dez. 2021 ISSN eletrônico: $2447-6498$

doentes pode ser chamado de medicina e que essa prática "sempre existiu", a medicina clínica tal como conhecemos tem no máximo duzentos anos. Essa é exatamente a ideia de ruptura epistemológica existente na obra de Canguilhem.

Para um leitor apressado, o texto pode trazer um certo nível de dificuldade, pois Canguilhem percorre um caminho que passa pelos filósofos mais antigos até os mais recentes. Estabelece uma linhagem de pensadores cuja relação com o pensamento vulgar não é de conteúdo, mas de forma - delineia-se o direito ao "conceito vulgar de saúde" em um horizonte transcendental (estaríamos longe do "a priori histórico" de Foucault?). Isso pode trazer a falsa impressão de que a história da filosofia seria equivalente a história da ciência. Contudo, Gaston Bachelard, epistemólogo e historiador da física e da química, ratifica que a história da filosofia, a história da arte e a história das ciências não compartilham um mesmo devir, jamais praticam as mesmas hierarquias (TILES, 2005). Segundo ele, tanto a primeira quanto a segunda são consideradas exemplares pois não se pode falar em progressão no mesmo sentido da história das ciências.

Evidentemente a questão do progresso ronda seu raciocínio como um fantasma. Mas de qualquer modo, com Bachelard propaga-se uma ênfase na noção de "problema científico" e de "problemática" em contraposição à pergunta ou "questão filosófica". Por um lado, busca-se a separação de um conjunto de concepções comuns através da noção de "obstáculo epistemológico", por outro lado, especialmente com Canguilhem, verifica-se uma ênfase em Kant e nos papéis do conceito na lógica transcendental, em detrimento do hegelianismo presente boa parte do pensamento francês do período.

Há conceitos vulgares, conceitos filosóficos e conceitos científicos na letra de Canguilhem, em que não se constata grande interesse por uma distinção cortante entre "problema científico" e "conceito fillosófico". Entretanto, como foi dito, não pode existir um conceito científico de saúde assim como não se pode erradicar a pretensão do vulgo em dizer o que é saúde, nem mesmo com a autoridade da ciência. Muito pelo contrário, parece-me que a filosofia estabelece uma aliança com estes enunciados autóctones e selvagens. Cabe, portanto, protegê-los e dialogar. É inclusive bastante curioso que a etnologia esteja ausente na reflexão de Canguilhem. Um conceito vulgar de saúde é por sua vez não somente legítimo como oferece um solo, que poderíamos chamar aqui de ético-estóico, para a reflexão filosófica sobre a saúde. 
Rev. Interd. em Cult. e Soc. (RICS), São Luís, v. 7, n. 2, p. 55- 79, jul./dez. 2021

ISSN eletrônico: 2447-6498

Enquanto conclusão seria preciso oferecer uma articulação do problema com a crise covid em curso, entendida a partir de impasses do campo biomédico e respostas insatisfatórias das ciências sociais e da filosofia. Vacinas e vírus criam novos corpos. Durante a crise covid observa-se um conflito generalizado de opiniões representativas de interesses em choque. Por outro lado, verifica-se a surpresa com o caráter pouco científico das apropriações científicas populares proporcionadas pela vida digital. Igualmente viu-se com espanto a dificuldade na aceitação de conceitos científicos e suas práticas. Me parecem boas palavras de ordem gritar pela ciência, exigi-la "baseada em evidência", insultar o terraplanismo etc. Parece-me, contudo, simplório, face aos esforços construtivistas em pensar as tecnociencias contemporâneas como um campo de controvérsias e apostas. As guerras de ciência e a interminável rede fatorial do covid19 apontam para lutas do antropoceno onde pensar a saúde se afigura decisivo. Organismos internacionais se viram bombardeados, atacados e vilipendiados. Na crisecovid, pretendiam ter adotado um conceito de saúde para uso universal, abusando de sua autoridade ao escamotear a políticas de captura conceitual e a ciência enquanto guerra, tentando promover uma área "livre de conflito" e "sem ideologias". Cabe doravante "introduzir as ciências na democracia”, para me expressar como Bruno Latour.

Já há algumas décadas que as noções populares sobre saúde, seja de enfermos ou quaisquer outros, tem sido reconhecidas e estudadas. Pratica-se a atenção para com tudo aquilo que circunda os conceitos esotéricos dos especialistas em saúde - o interesse justifica-se normalmente através do escopo da antropologia médica ou de uma busca por ajustar pesquisas clínicas a situações humanas. Em velocidade vertiginosa as disciplinas biomédicas se renovam, mas escondem controvérsias científicas usuais. Desde o surgimento da medicina baseada em evidência ficou mais difícil compreender as questões biomédicas sepultadas por cálculos estocásticos abstrusos, sob arenas cientométricas labirínticas. No mesmo diapasão, a vulgarização do círculo exotérico promoveu o Dr.Google à médico de família e autoridade desafiadora. A "experiência de doença" é um sólido conceito da epistemologia histórica de Canguilhem que pode ser mobilizado para pensar estes tempos de pandemia e antropoceno, além de outras reflexões correlatas como o "conceito vulgar de saúde".

Com a medicina baseada em evidência, a epidemiologia clínica e as tecnociências, o campo terapêutico transformou-se. Os conceitos filosóficos foram 
Rev. Interd. em Cult. e Soc. (RICS), São Luís, v. 7, n. 2, p. 55- 79, jul./dez. 2021 ISSN eletrônico: 2447-6498

encarcerados na lógica (bioética, filosofia analítica) e aqueles científicos se tornaram estocásticos em uma escala gigantesca, contra-intuitiva, distante do sensível e por vezes incompreensível e obscura.

O mesmo acontece com as ciências da Terra na catástrofe climática, que precisou de uma arena política apoiada no IPCC - os World Summits. Saber se uma máscara N95 funciona para diminuir a transmissão de um vírus leva tempo. A resposta pode ser parcialmente inconclusiva e coloca a experiência dos viventes para escanteio. A complexidade do adoecimento criou arenas transepistemicas complexas e múltiplas. A divulgação científica e a ciência-cidadã são dois esforços distintos para mitigar este abismo.

A saúde emerge como resistência a um ataque alienígena (covid-19, comunismo chinês, animal selvagem etc.) e mero problema discreto. Articulações e ramificações são tidas por paranoicas e substituídas pelo "inimigo interno" comunista, militante ecológico, ativista. Este é o panorama de muitas opiniões e conhecimentos em que perseveram os rumos neoliberais e ainda fazem um triplo esforço durante a maior crise planetária imaginável: tentam se justificar, buscam oferecer lucro ao $1 \%$, além de expectativas coletivas para o resto (blá-blá-blá segundo Thunberg). Talvez as maquinações da alt-right neonazista tenham deliberadamente promovido uma grande confusão. Contudo importa enxergar na politização dos debates, em sua moralização censora e ética cataclísmica, uma oportunidade para o exercício do pensamento filosófico. Uma abertura do pensamento para certo de-fora (dehors) da exfermidade covid19 sem o calaboca engenhoso, bacharelesco ou economês habitual (Estellita-Lins, 2020).

Adoecer é um luxo dos viventes saudáveis, reza a fórmula do filósofo mandarim. Nada mais estranho ao horror da enfermidade ou do envelhecimento cultivado pelas sociedades neoliberais. Este medo é calado pelos planos de saúde pois deve ser “curado" por dispositivos atuariais e securitários. Quem cuida de saúde hodierna é o mercado - resta saber qual: o mercado de Yuhan? Mercado da Soja? Nasdaq?

O "novo normal" e sua recusa militante ligou fortemente a crisecovid ao antropoceno. Esta conexão é igualmente letrada, em chicana, exige uma travessia ilustrada. Os conceitos científicos em profunda mutação neste momento buscam pensar uma saúde de Gaia, esta fina película de vida estendida e tensa sobre o planeta dos 
Rev. Interd. em Cult. e Soc. (RICS), São Luís, v. 7, n. 2, p. 55- 79, jul./dez. 2021 ISSN eletrônico: 2447-6498

terranos. Uma palavra de ordem se apresenta enquanto conceito vulgar: "Saúde é esquecer a pandemia”. Para alguns seria mais saudável silenciar sobre o assunto e prosseguir o jogo. Qual a o alcance e capacidade adaptativa deste enunciado? Como não perceber que o capitalismo odiado por muitos se apresenta aqui matreiramente como enunciado vital? O nome disso é business as usual: prosseguir os negócios de sempre enquanto o planeta frita e as zoonoses se tornam mais espertas. Emerge a questão das forças reparadoras da vida colocadas em um devir não-adaptativo, verdadeiramente transformador, sem as camadas de ocultação cosmética do virtual.

Do ponto de vista das narrativas de adoecimento pode-se suspeitar que a crise em curso engendrou uma pletora de narrativas de adoecimento. $\mathrm{O}$ direito ao conceito vulgar de saúde e seu a priori correlato invadiu os enunciados filosóficos através da proliferação midiática. De fato, todos ficaram enfermos de covid e produziram estranhas e interessantíssimas reflexões. Todos? Todos não. Somente aqueles que ficaram.

Somente os que estão enfermos de antropoceno, de zoonose e pandemia. Incluindo todos os mortos e todos os espíritos, encantados e santos.

\section{REFERÊNCIAS}

BING, François; BRAUNSTEIN, Jean-François. Entretien avec Georges Canguilhem. In: BING, François; BRAUNSTEIN, Jean-François; ROUDINESCO, Elisabeth (Orgs.). Actualité de Georges Canguilhem. Le normal et le pathologique. Paris: Les Empêcheurs de penser en rond, 1998, p. 134-148.

BRAUNSTEIN, Jean-François. Bioéthique ou philosophie de la médecine? Revue de métaphysique et de morale, v. 82, n. 2, p. 239-256, 2014.

CANGUILHEM, Georges. O Normal e o Patológico (1943). Rio de Janeiro: ForenseUniversitária, 1978.

CANGUILHEM, Georges. Études d'histoire et de philosophie des sciences concernant les vivants et la vie (1968). 7e rééd. Paris: Vrin, 1990.

CANGUILHEM, Georges. La Santé: concept vulgaire et question philosophique. In: Écrits sur la Médicine. 1. ed. Paris: Seuil, 2002, p. 49-68.

CANGUILHEM, Georges. Georges Canguilhem. CEuvres complètes, t. IV "Résistance, philosophie biologique et histoire des sciences 1940-1965. 1. ed. Paris: Vrin, 2015. 5v. (Coll. Bibliotheque des textes philosophiques,). 
Rev. Interd. em Cult. e Soc. (RICS), São Luís, v. 7, n. 2, p. 55- 79, jul./dez. 2021 ISSN eletrônico: 2447-6498

CAYGILL, Howard. A Kant Dictionary. Blackwell Philosopher Dictionaries. v. Oxford/Malden, Blackwell Publishers, p. 453, 1995.

EPICTETUS; ARRIAN. Epictetus. Discourses. Books one \& two. Vol. I. Text and translation by WA Oldfather. London \& New York: Harvard University Press/Heinemann, 1928. (Loeb Classical Library).

ESTELLITA-LINS, Carlos. Exfermidade, enfermidade ou experiência de doença: zoonose e antropoceno. O que nos faz pensar, v. 29, n. 47, p. 192-237, 2020.

GIROUX, Élodie. Après Canguilhem, définir la santé et la maladie. Paris: PUF, 2010.

GIROUX, Élodie. Le Concept Théorique de Santé. Presentation du texte de Christopher Boorse. In: Philosophie de la médecine II. Paris: Librairie philosophique J. Vrin, 2012, p. 53-59.

HERSHBELL, Jackson. The Stoicism of Epictetus: Twentieth Century Perspectives. In: HAASE, Wolfgang (Org.). Philosophie, Wissenschaften, Technik. Philosophie (Stoizismus). Berlin, Boston: De Gruyter, 1989.

JAGU, Amand. Épictète et Platon: Essai sur les relations du Stö̈cisme et du Platonisme à propos de la Morale des Entretiens. Paris: Librairie Philosophique J. Vrin, 1946.

PETERS, Francis E. Greek philosophical terms: A historical lexicon. New York: NYU Press, 1967.

SOUTO, Caio. O vitalismo crítico de Georges Canguilhem. O que nos faz pensar, v. 29, n. 48, p. 212-231, 2021.

TILES, Mary. Technology, Science, and Inexact Knowledge: Bachelard's NonCartesian Epistemology. Continental philosophy of science, p. 157-175, 2005. 